\title{
Identifying and meeting the challenges of insulin therapy in type 2 diabetes
}

\author{
This article was published in the following Dove Press journal: \\ Journal of Multidisciplinary Healthcare \\ 2 July 2014 \\ Number of times this article has been viewed
}

\author{
Christopher Sorli',* \\ Michael K Heile ${ }^{2, *}$ \\ 'Billings Clinic Research Center, \\ Billings, MT, USA; ${ }^{2}$ The Family \\ Medical Group Glenway, \\ Cincinnati, OH, USA \\ *Both authors contributed equally \\ to this work
}

Correspondence: Christopher Sorli Billings Clinic Research Center, 1045 North 30th Street, Billings, MT 5910I, USA

Tel +l 4062382500

Fax +I 4062382413

Email csorli@billingsclinic.org

\begin{abstract}
Type 2 diabetes mellitus (T2DM) is a chronic illness that requires clinical recognition and treatment of the dual pathophysiologic entities of altered glycemic control and insulin resistance to reduce the risk of long-term micro- and macrovascular complications. Although insulin is one of the most effective and widely used therapeutic options in the management of diabetes, it is used by less than one-half of patients for whom it is recommended. Clinician-, patient-, and health care system-related challenges present numerous obstacles to insulin use in T2DM. Clinicians must remain informed about new insulin products, emerging technologies, and treatment options that have the potential to improve adherence to insulin therapy while optimizing glycemic control and mitigating the risks of therapy. Patient-related challenges may be overcome by actively listening to the patient's fears and concerns regarding insulin therapy and by educating patients about the importance, rationale, and evolving role of insulin in individualized self-treatment regimens. Enlisting the services of Certified Diabetes Educators and office personnel can help in addressing patient-related challenges. Self-management of diabetes requires improved patient awareness regarding the importance of lifestyle modifications, self-monitoring, and/or continuous glucose monitoring, improved methods of insulin delivery (eg, insulin pens), and the enhanced convenience and safety provided by insulin analogs. Health care system-related challenges may be improved through control of the rising cost of insulin therapy while making it available to patients. To increase the success rate of treatment of T2DM, the 2012 position statement from the American Diabetes Association and the European Association for the Study of Diabetes focused on individualized patient care and provided clinicians with general treatment goals, implementation strategies, and tools to evaluate the quality of care.
\end{abstract}

Keywords: type 2 diabetes, barriers, patient education, individualized therapy, self-management, insulin, insulin analogs, insulin pens, emerging technologies

\section{Introduction}

Advances in technology and an increased understanding of the role of insulin in the complexity of both glycemic homeostasis and energy homeostasis have led to insulin preparations that more closely mimic the endogenous pattern of insulin release. ${ }^{1}$ Data from the landmark United Kingdom Prospective Diabetes Study 49 on the use of monotherapy, combined with data from United Kingdom Prospective Diabetes Study 28 on combination therapy, led the authors to conclude that after 9 years, a substantial number - possibly the majority - of patients with type 2 diabetes mellitus (T2DM) will require insulin to reach the goal of hemoglobin $\mathrm{A}_{1 \mathrm{c}}\left(\mathrm{HbA}_{1 \mathrm{c}}\right)<7.0 \%(<53.0 \mathrm{mmol} / \mathrm{mol}){ }^{2,3}$ To bring and to maintain patients to goal earlier in their disease process, instead of being the treatment of last resort, for many patients, insulin should be instituted much earlier 
in the disease process as part of an individualized preventive treatment strategy. Early intensive insulin therapy in patients with newly diagnosed T2DM significantly improved $\beta$-cell function and remission rates from hyperglycemia compared with treatment with oral antidiabetic agents. ${ }^{4}$ The recent introduction of new therapeutic agents for glycemic control offers more treatment options, but it also raises questions among clinicians as to when and how insulin should be initiated in patients with T2DM.

The ultimate goal of glycemic management in diabetes is to safely achieve and maintain glucose and energy homeostasis close to normal levels to slow, and even prevent, the complications of hyperglycemia. ${ }^{5}$ Early use of insulin therapy in T2DM may result in a reduction in chronic glucotoxicity, which increases the rate of $\beta$-cell apoptosis and deterioration in $\beta$-cell function. ${ }^{6-8}$ Because of the pathogenesis and progressive nature of T2DM, the majority of patients with T2DM will ultimately require insulin therapy., ${ }^{2,9}$ Subset analyses of several studies have demonstrated that intensive glycemic control in patients with a shorter duration of T2DM and no established atherosclerosis may lower the risk of developing cardiovascular complications ${ }^{10}$ and positively affect both the macro- and microvascular prognosis. ${ }^{5}$ Although the administration of basal insulin glargine more effectively reduced the incidence of new-onset diabetes in patients with impaired glucose tolerance than standard treatment, it caused an increased incidence of hypoglycemia and a modest increase in weight, and therefore the risk/benefit ratio for early initiation of basal insulin continues to be debated. When the decision is made to intensify, consideration should be given to early initiation of detemir and glargine for their favorable safety and efficacy profiles. ${ }^{11-13}$

Current American Diabetes Association (ADA)/ European Association for the Study of Diabetes (EASD) treatment guidelines cited the recommendation for more stringent $\mathrm{HbA}_{1 \mathrm{c}}$ targets (6.0\%-6.5\% [42.1-47.5 mmol/mol]) in selected patients, ${ }^{13}$ although higher goals, such as $8.0 \%$ (63.95 $\mathrm{mmol} / \mathrm{mol})$, may be more appropriate for patients with severe hypoglycemia, limited life expectancy, advanced microvascular or macrovascular complications, long durations of comorbid conditions, and extensive history of inability to meet the goal of greater glycemic control. ${ }^{14}$ Such stringent glycemic control usually requires combination therapy that, if initiated early, offers the best chance of modifying the disease process and preserving quality of life. Conversely, less stringent $\mathrm{HbA}_{1 \mathrm{c}}$ targets $(7.5 \%-8.0 \%$ [58.5-63.9 $\mathrm{mmol} / \mathrm{mol}]$ or even slightly higher) are appropriate for patients with a history of severe hypoglycemia, and those for whom the glycemic target is difficult to attain despite therapy and lifestyle modifications. ${ }^{13,15}$

A study of 17,306 US patients with diabetes found that only $57 \%$ had $\mathrm{HbA}_{1 \mathrm{c}}$ levels that met the 2011 ADA goal of $<7.0 \%$ (<53.0 mmol/mol). ${ }^{13,16,17}$ The 2012 ADA/EASD position statement also cited the recommendations by the $2011 \mathrm{ADA}^{17}$ regarding initiation of metformin therapy and lifestyle modification upon diagnosis of T2DM, unless metformin is contraindicated. ${ }^{13}$ Additionally, starting treatment with a combination of two noninsulin agents or with basal insulin in patients with a baseline $\mathrm{HbA}_{1 \mathrm{c}} \geq 9.0 \%$ ( $\geq 74.9 \mathrm{mmol} / \mathrm{mol}$ ) may be justified because of the low probability of achieving glycemic control on monotherapy. ${ }^{13,18}$ Therefore, if a patient presents with significant hyperglycemic symptoms and/or if the $\mathrm{HbA}_{1 \mathrm{c}}$ level is between $10.0 \%-12.0 \%$ ( $85.8-107.7 \mathrm{mmol} / \mathrm{mol})$, insulin therapy should be strongly considered from the outset. ${ }^{13}$

Guidelines from the American Association of Clinical Endocrinologists (AACE) and the American College of Endocrinology (ACE) recommend initiating insulin therapy in symptomatic patients with $\mathrm{HbA}_{1 \mathrm{c}}>9.0 \%$ $(>74.9 \mathrm{mmol} / \mathrm{mol}) .{ }^{19}$ All of these factors demonstrate the benefits of individualized treatment plans aimed at optimizing glycemic targets. ${ }^{13}$

Despite the efficacy of insulin therapy, it is used in $<50 \%$ of the patients for whom it is recommended and with poor patient adherence. ${ }^{20}$ One-third of insulin-naïve patients who are prescribed insulin do not become ongoing users, ${ }^{21}$ and almost $60 \%$ of patients miss injections, with $20 \%$ missing doses on a regular basis. ${ }^{22}$ Challenges to insulin therapy may present an even greater hurdle in clinical practice settings that are not specialized in intensive diabetes care or where educational resources are limited.

Challenges associated with insulin use in T2DM treatment are often grouped into three categories: 1) clinician-related challenges; 2) patient-related challenges; 3) and health care system-related challenges. This review will discuss issues encountered by clinicians and patients in the initiation and intensification of insulin therapy; recent advances in insulin therapy and delivery; and practical strategies health care providers (HCPs) can implement to overcome these challenges.

\section{Methods}

Articles addressing clinician-, patient-, and health care system-related challenges of insulin therapy in patients with T2DM were identified by a literature search in PubMed covering the period of 1990-2013. The search terms used 
included: "insulin therapy"; "type 2 diabetes"; "adults"; "challenges and/or barriers"; "clinicians and/or physicians"; and "healthcare and/or health care". Selection was limited to English-language, peer-review articles. The search was further refined to include articles addressing clinician-, patient-, and health care system- related challenges of insulin therapy initiation. Internal references were also used if they were applicable to the discussion. In addition, the authors' clinical experience with T2DM was utilized to analyze the literature to assist HCPs with the assessment and treatment of patients with T2DM. Also, 115 articles were included and reviewed in this paper.

\section{Results}

\section{Clinician-related challenges}

\section{Understanding and overcoming clinical inertia}

Clinicians often are slow to initiate or intensify therapy, a behavior defined as "clinical inertia" that involves recognition of the problem but failure to act. ${ }^{23} \mathrm{Clinical}$ inertia may be caused by: an overestimation of the care provided; perception by the clinician that glycemic control is improving or that the patient is not compliant to diet and exercise; ${ }^{24}$ lack of proper clinical training; and the absence of focus on achieving patients' therapeutic goals. ${ }^{23}$

Historically, insulin has been initiated as last resort therapy to help patients with advanced diabetes achieve and maintain their therapeutic goals. Only $18 \%$ of patients who were receiving combination therapy with oral antidiabetes agents were switched to insulin before their $\mathrm{HbA}_{1 \mathrm{c}}$ exceeded $8.0 \%$ (63.9 mmol $/ \mathrm{mol}) .{ }^{25} \mathrm{Hypothetically,} \mathrm{the} \mathrm{average} \mathrm{patient}$ in this study would have spent 5 years with an $\mathrm{HbA}_{1 \mathrm{c}}>8.0 \%$ $(63.9 \mathrm{mmol} / \mathrm{mol})$ and 10 years with an $\mathrm{HbA}_{1 \mathrm{c}}>7.0 \%$ ( $>53.0 \mathrm{mmol} / \mathrm{mol}$ ) before insulin was initiated. ${ }^{25}$

A survey of 600 primary care physicians (PCPs) and specialists who treat patients with diabetes indicated that the lack of experience in initiating insulin and time to educate patients present challenges to insulin intensification. ${ }^{26}$ While $92 \%$ of respondents agreed that insulin intensification is an essential component of diabetes management, more than $20 \%$ of them never initiated or modified insulin therapy. ${ }^{26}$ In addition, $49 \%$ of the surveyed physicians indicated that not staying current with advances in insulin therapies or delivery methods is one of the main challenges to insulin initiation. ${ }^{26}$ Because this was a multinational study, it is important to consider the geographical difference in diabetes management. PCPs who treat fewer numbers of patients with T2DM are more reluctant to initiate insulin therapy compared with those who treat a greater number of patients. ${ }^{27}$
Approximately $40 \%$ of PCPs who treat patients with T2DM believed insulin initiation would be unnecessary if patients followed their physician's recommendations, and that training patients in the proper administration and use of insulin is overly time consuming for the staff. ${ }^{27}$ Uncertainty about insulin dosing, concerns about individualizing insulin therapy, ${ }^{28}$ and the lack of consensus among national guidelines and recommendations can also increase clinical inertia on the part of clinicians about appropriate glycemic targets. ${ }^{19,29,30}$ Clinicians should consider these guidelines within the context of the needs, preferences, and tolerances of each patient with a patient-centered approach that uses individualized treatment. ${ }^{13}$

Although T2DM is a progressive disease and the majority of patients will ultimately require insulin therapy, ${ }^{2,9}$ some physicians consider initiation of insulin therapy a personal failure to control their patients' diabetes with oral antidiabetic agents and feel that they must force their patient to accept insulin therapy. To overcome this challenge, clinicians should actively listen to patients' concerns and/or fear regarding insulin therapy and explain that type 2 diabetes is a progressive disease and that $\beta$-cell failure is common. ${ }^{31}$ For example, if the patient is concerned about insulin-induced hypoglycemia, the clinician can explain that newer longand short-acting insulin analogs are less likely to cause hypoglycemia compared with older insulin preparations and that severe hypoglycemia is seen mainly in patients with type 1 diabetes mellitus (T1DM). ${ }^{31}$

\section{Hypoglycemia}

Hypoglycemia is a primary safety concern for both clinicians and patients; it represents a major challenge to glycemic control. Minor hypoglycemic episodes are significant, as frequent minor events increase the risk for severe hypoglycemia ${ }^{32}$ via the development of hypoglycemia unawareness. Although few hypoglycemic episodes manifest as "severe" (requiring assistance from another person to remedy), ${ }^{33}$ severe episodes may cause significant morbidity, and - sometimes - death. ${ }^{34-37}$

Anxiety and/or fear in both patients and physicians can interfere with glycemic control. ${ }^{32}$ Patients who experience hypoglycemia, particularly severe hypoglycemia, may be reluctant to maintain or self-adjust their insulin regimen, resulting in chronic hyperglycemia. ${ }^{38}$ Additionally, nocturnal hypoglycemia is likely to be underreported because patients may not awaken or recognize the symptoms. ${ }^{39}$ Because physiologic and symptomatic defenses that combat hypoglycemia are suppressed during sleep, mild or moderate hypoglycemic 
episodes may progress to more severe episodes, with more serious consequences. ${ }^{39,40}$

Risk factors for hypoglycemia associated with insulin therapy include: poorly timed insulin administration; lack of recognition of increased tissue sensitivity to insulin; increased glucose utilization following exercise; and inappropriate use of insulin or insulin secretagogues. ${ }^{32}$ All of these risk factors can be reduced with timely initiation of therapy using currently available insulin formulations and technologies (insulin pumps and monitoring), and proper patient education, which should empower physicians to overcome their inertia.

Although events of hypoglycemia are more common in individuals with T1DM, they also occur relatively frequently in patients with T2DM using insulin and/or sulfonylurea therapy. Because T2DM is approximately 20 times more prevalent than T1DM, and most of these patients will ultimately require insulin therapy due to a progressive decline of $\beta$-cell function, a greater number of hypoglycemic episodes, including severe hypoglycemia, are seen in patients with T2DM. ${ }^{32}$ Advances in insulin therapy can help address physicians' concerns about hypoglycemia. For example, as discussed below, basal insulin analogs are associated with a reduced risk of hypoglycemia ${ }^{41-44}$ and, importantly, reduced nocturnal hypoglycemia in both T1DM and T2DM. ${ }^{45}$

\section{Strategies to manage weight gain}

Weight gain and fluid retention are also common side effects of insulin therapy. Since the majority of patients with T2DM are overweight, clinicians may be reluctant to initiate and intensify insulin therapy in these patients because of the potential for additional weight gain with insulin therapy, which can exacerbate insulin resistance. Compared with neutral protamine Hagedorn (NPH), basal insulin analogs, particularly detemir, have consistently produced less weight gain. ${ }^{43,44}$ Additionally, clinicians can initiate an appropriately titrated basal insulin regimen, coupled with the timely use of mealtime insulin, to reduce weight gain and hypoglycemia. In addition to controlling T2DM, new evidence suggests that the addition of a glucagon-like peptide 1 receptor agonist (GLP-1RA) to insulin glargine abrogates the weight gain associated with insulin and leads to weight loss. ${ }^{46}$

\section{Managing time concerns}

In 2007, in the US, PCPs diagnosed approximately $65 \%$ of cases of T1DM and T2DM. ${ }^{47}$ In one survey, two-thirds of PCPs indicated that the initiation of insulin and time needed to train patients are two of the most difficult aspects of managing patients with T2DM. ${ }^{27}$ Because clinician nurses are often involved in insulin initiation, they will also benefit from protocols for implementing insulin initiation, hands-on training, and local support services. ${ }^{48}$ Access to education is often limited, and without adequate professional training, insulin initiation may be both delayed and suboptimal. ${ }^{29,49}$

Unfortunately, only $44 \%$ of PCPs in the US have access to a Certified Diabetes Educator (CDE), ${ }^{26}$ the majority of whom are not members of the PCPs' staff. This forces clinicians to send patients to another office to see the CDE; this slows the process, disrupts continuity of care, and may result in miscommunication. These educational resources may be limited or unavailable to some patients.

Although patient education is a time consuming task for physicians, ${ }^{27}$ clinicians should give patients the time to express their fears and concerns about insulin therapy, thereby identifying preexisting misconceptions and addressing them accordingly. ${ }^{31}$ For example, physicians often overestimate the patient's fear of injection pain, making a preemptive decision to delay or withhold insulin, when in fact - one study showed that fear of pain ranked fairly low among patients. ${ }^{50}$ The majority of PCPs agree that the potential for insulin to prevent or to delay complications far outweighs the risks of weight gain and hypoglycemia. ${ }^{27}$ Practical, time-efficient solutions that will help educate patients on the importance of treatment adherence, the proper administration of insulin, and overcome the time concern challenge are presented here.

\section{Patient-related challenges}

\section{Balancing complexity of insulin regimen with health-related quality of life potential}

Patient perception that insulin therapy is too complicated and time consuming can interfere with its timely initiation. ${ }^{51,52}$ A psychological insulin resistance self-report survey was conducted in a large multicity sample of insulin-naïve patients with T2DM. Almost 50\% of insulin-naïve patients believed themselves incapable of managing an insulin regimen, and that such therapy would restrict their lifestyle. ${ }^{51}$ Indeed, some tasks, such as determining dosages and handling syringes and vials, can be overwhelming for some patients. Less complex dosing can improve patient adherence, while inflexible complex dosing is often cited as a reason for missing insulin doses. ${ }^{53}$ A survey of 1,250 physicians who treat patients with T2DM and a telephone survey of 1,530 insulin-treated patients in the US and several other countries revealed that two-thirds of the patients felt that diabetes controlled their 
lives and that treatment regimens were too restrictive. ${ }^{54}$ Additionally, $28.2 \%$ of patients surveyed reported that they would be unwilling to take insulin if their physician prescribed it. ${ }^{51}$

Basal-bolus insulin therapy, which can minimize postprandial glucose (PPG) excursions and maintain glycemic control, ${ }^{55}$ can be particularly challenging for patients. However, this regimen likely leads to the highest improvements in health-related quality of life. ${ }^{55}$ With proper patient education, patients can match insulin to food choices to maintain glycemic control and avoid weight gain. Basal-bolus regimens that are simpler to follow may provide an effective strategy. One study compared the stepwise addition of aspart to either the largest meal (titration based on premeal glucose values) or the meal with the largest prandial glucose increment, in 296 individuals with T2DM inadequately controlled on basal insulin and oral antidiabetes agents. ${ }^{56}$ The stepwise addition of bolus insulin based on either premeal or postmeal glucose values was equally effective for intensifying therapy in patients with T2DM. ${ }^{56,57}$ Another study yielded similar results for the stepwise addition of prandial insulin in patients requiring intensification beyond basal insulin. ${ }^{57}$

Achieving glycemic control with insulin therapy depends to a great extent on educating patients regarding their condition, self-management strategies, and available therapeutic options. Developing less complex treatment plans that meet the glycemic goals may also provide an effective treatment strategy. Given the improved risk-benefit ratios of insulin analogs compared with older formulations, physicians should make informed decisions based on current information on evolving new insulin formulations that highlight the benefits of a preventive, pathophysiologic approach to treatment.

\section{Meeting patient convenience needs}

The pharmacokinetic and pharmacodynamic limitations of older insulin therapies can make the use of insulin therapy more challenging. Regular human insulin (RHI) has traditionally been used to replace the endogenous spike in insulin production immediately following meals. Due to its slow absorption rate and onset of action, RHI should optimally be administered 30-45 minutes before a meal, which can present logistical difficulties. ${ }^{52,58}$ Injecting RHI too early or too late will result in hypoglycemia or late postprandial hypoglycemia, respectively. Unlike RHI, the rapid-acting insulin analogs lispro, aspart, and glulisine are absorbed more quickly, have an earlier and higher insulin peak concentration, and a shorter duration of action than RHI. ${ }^{58,59}$ Therefore, rapid-acting insulin analogs can be administered at meal time, although administration 10-15 minutes before the meal is recommended to optimize control of postprandial glycemic excursions. Compared to RHI, these formulations offer greater convenience, improvement of PPG excursions, and reduction of late postprandial hypoglycemia. ${ }^{58-62}$

Basal insulin analogs glargine and detemir provide consistent and relatively flat, long-acting insulin levels that mimic the constitutive secretion pattern of endogenous insulin, which provides continuous coverage. ${ }^{63-67}$ Currently available basal insulin analogs are dosed once daily in the majority of patients, but they should be dosed at the same time every day to optimize control. In some patients, basal insulin analogs can be dosed twice daily to provide flatter basal insulin coverage (24-hour coverage). ${ }^{66,68,69}$ Emerging long-acting basal insulins (eg, insulin degludec), which can be administered once daily in all patients and at any time of day without compromising glycemic control, might better address patient convenience and fear of hypoglycemia. ${ }^{70-72}$

\section{Destigmatizing needles}

Recent advances in needle technology have made insulin injections more accurate, less painful, more discreet, and convenient to use than vials and syringes. ${ }^{73-75}$ Use of insulin pens can overcome some of the patient-related challenges (stigma and fear) to initiation of insulin therapy. ${ }^{74-76}$

\section{Overcoming common misperceptions about insulin}

Most patients perceive the initiation of insulin therapy as a reflection on their own failure to manage their disease ${ }^{51,52,77,78}$ and that insulin is not effective or may even cause harm. ${ }^{21,78}$ In a study of patients who accepted insulin therapy, but did not become long-term users, major predictors of insulin nonadherence included the negative impact of insulin on social and work lives, injection phobia, and concerns about side effects. ${ }^{21}$ Nearly one-half of the patients who did not adhere to insulin therapy believed that people who require insulin "have not taken care of themselves in the past", and $35 \%$ believed that insulin causes harm. ${ }^{21}$ Because patients with T2DM tend to be obese, slight weight gain may have an impact on glycemic control. ${ }^{52,79}$ Moreover, fear of hypoglycemia is a major cause of nonadherence and resistance to insulin initiation in these patients. ${ }^{51}$ Interestingly, patients who did not adhere to insulin treatment frequently believed their clinician did not adequately explain the benefits and risks of insulin therapy. ${ }^{21}$ These are legitimate concerns that need to be addressed by the treating clinician. Therefore, the optimal time to educate patients about insulin therapy is soon 
after diagnosis, or early in the course of the disease, as this time frame offers clinicians the opportunity to destigmatize insulin use and address patient concerns.

\section{Cost of insulin therapy}

The cost of insulin is another patient-related challenge. Although long-acting basal insulin analog therapy is associated with lower rates of hypoglycemia, this therapy is costly compared to conventional insulins. ${ }^{80}$ However, for some patients who are at high risk of hypoglycemia, the use of insulin analogs may prove to be cost-effective compared with the additive cost of treating a single extra hypoglycemic event. ${ }^{80-83}$ Cost-effectiveness of insulin analogs depends on the type of insulin analog, whether the patients have T1DM or T2DM, and the country in which they reside. ${ }^{80,84} \mathrm{HCPs}$ are advised to consider the full costs associated with the use of insulin therapy rather than the cost of insulin alone. ${ }^{85}$

\section{Health care system-related challenges}

The Medicare Part D program provides prescription drug coverage for Medicare beneficiaries. One unique feature of this program is the coverage gap (or "donut hole"). In 2008, benefits included a deductible and $25 \%$ copayment for drug spending between $\$ 275-\$ 2,510$. After the initial coverage period, beneficiaries entered a coverage gap, in which they paid $100 \%$ of the drug cost until their true out-of-pocket drug spending reached the catastrophic limit of $\$ 4,050$. Under the catastrophic coverage, beneficiaries pay the greater of a $5 \%$ or a $\$ 2.25$ or $\$ 5.60$ copayment for generic or brand-name drugs, respectively. ${ }^{86} \mathrm{Gu}$ et al analyzed adherence to antidiabetic agents in a sample of 12,881 Medicare Part D beneficiaries with diabetes who had three different levels of coverage: 1) no coverage; 2) generic drug coverage only; and 3) both generic and brand-name drug coverage. ${ }^{86}$ The study demonstrated that the coverage gap in the Medicare Part D program has a significant negative impact on medication adherence among beneficiaries with diabetes and that the availability of brandname drug coverage is important to the adherence to diabetes medications. Likewise, in a cohort of patients intensifying their basal insulin therapy with the addition of mealtime insulin, one of the risk factors associated with poor persistence to mealtime insulin therapy was increased average insulin copayment. ${ }^{87}$ Increased levels of copayments were found to be a significant barrier to optimal adherence after conversion to pen therapy from vial and syringe therapy in patients with T2DM treated in a managed care setting. ${ }^{88}$ Another study that compared the cost of thiazolidinedione or insulin therapy for the treatment of patients with uncontrolled T2DM demonstrated that the cost of therapy with thiazolidinedione was substantially lower than that of insulin therapy in the first year. This is because patients receiving insulin therapy need to use more blood glucose monitoring strips and need to attend an educational session. However, in year 2 and year 3 , the costs of the two therapies were comparable. ${ }^{89}$

\section{Evolution of insulin technology}

Advances in the understanding of the pathophysiology of T2DM over the last 2 decades and the technological and biochemical advances in insulin analogs have enabled clinicians to more closely mimic the basal and prandial insulin secretory profiles seen in normoglycemia, progress that might help overcome the challenges associated with insulin therapy. All insulins manufactured for therapeutic purposes in the US are the altered basic human insulin molecule with altered absorption profile..$^{90}$

\section{Rapid-acting insulin analogs}

Human insulin has a natural propensity to form hexamers in the pancreas during storage in the $\beta$-cell, ${ }^{91}$ resulting in slow absorption into the circulation. Upon extracellular release, hexamers then dissociate into dimers and monomers, which are the biologically active form of insulin. Rapid-acting insulin analogs have a lowered propensity to form hexamers, and injection of rapid-acting insulin analogs results in quick absorption into the circulation and earlier and higher insulin peak concentration. ${ }^{59}$ Rapid-acting analogs are thus better suited, pharmacologically, to meet the PPG surge. Patients using rapid-acting insulin analogs had lower rates of hypoglycemia compared to older-generation, short-acting insulin formulations (Table 1). ${ }^{62,92,93}$

\section{Long-acting insulin analogs (basal insulin)}

The unique and more predictable pharmacokinetic and pharmacodynamic properties of basal insulin analogs offer significant advantages over NPH. Basal insulin analogs glargine and detemir more effectively mimic the constitutive secretion of endogenous insulin, reduce glycemic variability, and are absorbed more slowly and consistently than NPH. This profile results in a longer duration of action, a flatter pharmacodynamic profile, and better glycemic control. ${ }^{41,59,94}$ Detemir has a lower coefficient of variability than either glargine or $\mathrm{NPH}^{94}$ and is the only basal insulin commercially available that does not form microcrystals in the subcutaneous space. Use of detemir in combination with metformin or a GLP-1 receptor agonist may minimize weight gain. ${ }^{95}$ Moreover, basal insulin analogs significantly reduce the rate of hypoglycemia 


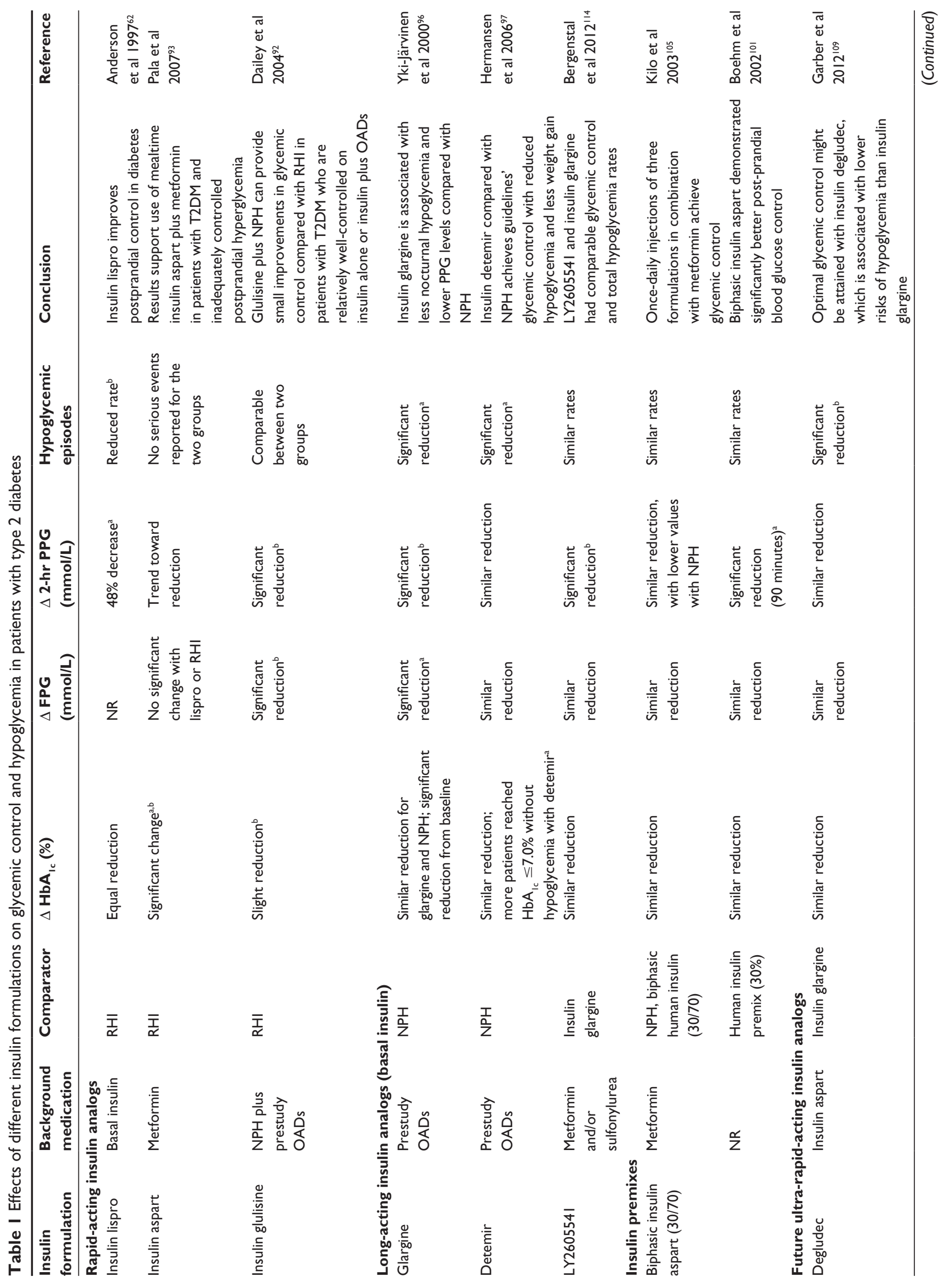




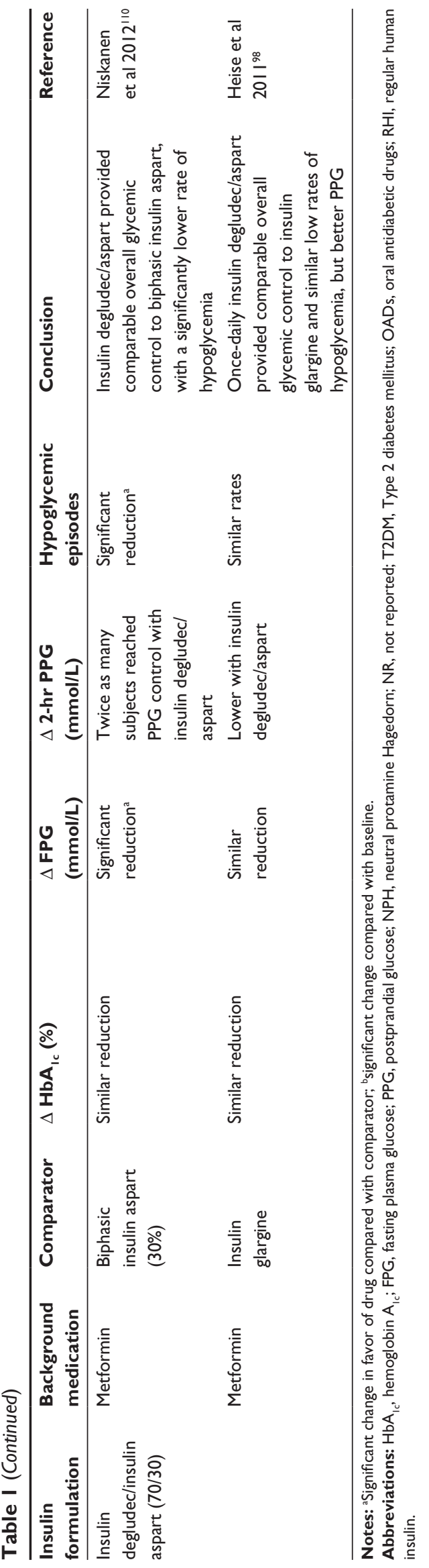

compared with $\mathrm{NPH}^{96,97}$ and patients who achieved fasting plasma glucose (FPG) targets experienced less symptomatic hypoglycemia (Table 1). ${ }^{96}$ Therefore, the AACE does not recommend NPH due to its increased risk for hypoglycemia compared to basal insulin analogs. ${ }^{19}$

Although currently available basal insulin analogs offer several advantages over NPH, they do not completely reproduce the physiological basal insulin secretion profile, which continues to be an unmet need in the treatment of diabetes. ${ }^{98,99}$ At higher doses, the profile of glargine and detemir show a slight rise and fall in insulin activity, ${ }^{99}$ and when $<25$ units daily are used in insulin-sensitive individuals, they do not always achieve 24-hour coverage. ${ }^{68}$ Basal insulins also lack postprandial coverage and should be dosed at the same time every day to ensure optimal control. These limitations may, in part, explain why basal insulin treatment for patients with T2DM may fail to reach and maintain $\mathrm{HbA}_{1 \mathrm{c}}$ goals.

\section{Insulin premixes}

Insulin premix therapy is a useful option for patients who require prandial insulin coverage but are not able or willing to use multiple daily injections. ${ }^{100}$ Biphasic insulin analogs, which consist of part insulin analog and part protaminated version of the same analog, have a more physiological profile compared to human insulin premixes. Premixed insulin analogs can be injected at mealtimes, providing greater patient convenience and dosing flexibility. They may also be associated with a lower risk of major hypoglycemia than human insulin premixes, ${ }^{101}$ which should be administered $30-40$ minutes before meals. Biphasic insulin analogs can be dosed once, twice, or three times daily, depending on patient's needs, ${ }^{102-105}$ and once-daily administration of biphasic insulin analog at dinner time in combination with metformin has been shown to be effective for many patients. ${ }^{105}$ Insulin analog premixes are also available in a variety of long- to short-acting dosing ratios: 75/25; 70/30; and 50/50. These formulations are better suited to those who eat regularly and consistently.

\section{Future formulations}

\section{Ultra-long-acting insulin degludec}

Current basal insulins possess pharmacokinetic and pharmacodynamic properties that are superior physiologically to NPH, but still do not meet the criteria of an ideal basal insulin. ${ }^{106}$ These characteristics include: an ultra-long-action profile allowing for once per day dosing in all patients; a flat time-action profile with a very low level of day-to-day variability minimizing both hypoglycemia and hyperglyce- 
mia; and the ability to tailor therapy to the individual patient by allowing for flexible dosing schedules. ${ }^{106}$ Insulin degludec forms soluble multihexamers upon subcutaneous injection, resulting in an ultra-long-action profile of $>42$ hours, a long half-life ( $>24$ hours), and a smooth and stable pharmacokinetic profile at steady state. ${ }^{107,108}$ In a 1 -year trial in patients with T2DM, insulin degludec given with aspart improved FPG and long-term glycemic control with a significantly lower risk of overall and nocturnal hypoglycemia compared to glargine with aspart (Table 1). ${ }^{109}$ Insulin degludec was studied in one trial using extreme dosing in patients with T2DM, to create intervals of 8-40 hours between doses. ${ }^{70}$ Insulin degludec was associated with significantly less nocturnal hypoglycemia $(P=0.0031)^{71}$ in both the fixed and flexible populations and had the added convenience of flexible daily injections compared to that of conventional basal-bolus therapy. Another study demonstrated that in T1DM, degludec can be administered flexibly at any time of day with similar glycemic control and less nocturnal hypoglycemia compared with glargine given once daily at the same time for 52 weeks. ${ }^{72}$ Insulin degludec significantly reduced variability in insulin action when compared with glargine and lowered the rates of hypoglycemia, ${ }^{109}$ as well as significantly reduced hypoglycemic episodes during the maintenance period. ${ }^{109}$

\section{Ultra-long-acting insulin degludec/aspart}

A combination of degludec and aspart is in development. Because of its unique molecular modification, insulin degludec is the first basal insulin analog that can be combined with a rapid-acting insulin analog while preserving the pharmacokinetic profile and the efficacy of the individual insulins (Table 1)..$^{98,110}$

\section{Ultra-rapid-acting insulin BIOD-095, BIOD-I05, and BIOD-I07}

When a novel combination of excipients is used to modify the insulin hexamer complex, it results in a more rapid dissociation of the hexamers into monomers and dimers following subcutaneous injection. ${ }^{111}$ Ethylenediaminetetraacetic acid, in conjunction with citric acid or sodium citrate to sequester zinc, works to destabilize the insulin hexamer. After injection and dilution in the subcutaneous milieu, BIOD095 rapidly disassembles into smaller monomeric/dimeric subunits. ${ }^{112}$ BIOD-105 and BIOD-107 are two new ultrarapid-acting human insulin formulations with added citrate, ethylenediaminetetraacetic acid, and calcium. BIOD-105 and BIOD-107 showed local injection discomfort comparable to insulin lispro, with more rapid initial absorption and lower peaks and longer durations of effect compared with insulin lispro. ${ }^{113}$

\section{Long-acting PEGylated LY260554 I}

LY2605541 is a novel once-daily, long-acting basal insulin that is coupled to polyethylene glycol (PEGylated) to delay absorption and clearance. LY2605541 demonstrated comparable glucose control with a more reduced intraday variability, lower rates of nocturnal hypoglycemia, and more weight loss compared with insulin glargine (Table 1). ${ }^{114}$

\section{Insulin delivery: pen devices}

Technological advances in insulin delivery systems include the development of smaller and finer insulin needles, insulin pens, and insulin pumps. Use of either prefilled disposable or reusable pens can overcome some of the patient challenges to initiation of insulin therapy and may improve patient adherence and, possibly, patient outcomes. ${ }^{76}$ A study comparing a modified five-bevel needle pen tip (available globally since 2005) with that of a marketed three-bevel needle pen tip showed that pen geometry affects the penetrating force and, consequently, patient preferences. ${ }^{73}$ Moreover, compared to vials and syringes, insulin pens are preferred because they are easy to use, convenient, and deliver a precise and controlled amount of insulin. ${ }^{115}$ Additionally, insulin pens have visual and audible indicators to assist with dose setting and delivery that ensure dosing accuracy and reduce the risk of medication errors. ${ }^{116}$ Pens are associated with lower rates of hypoglycemia, ${ }^{117,118}$ and patient preference and treatment satisfaction scores, ${ }^{74}$ greater adherence and persistence, ${ }^{117,119}$ and, consequently, greater glycemic control. ${ }^{116}$

\section{Insulin delivery: pumps}

Given the increasing demand for insulin therapy in T2DM and the inability of single-insulin regimens to achieve long-term glycemic control, continuous subcutaneous insulin infusion (CSII) with insulin pumps has become a popular alternative to the use of single or multiple daily injections of insulin. ${ }^{120}$ The CSII provides precise amounts of rapid-acting analog insulin at a continuous basal rate to control glucose when the patient is not eating and as a meal and correction bolus to account for food intake and glucose values that are out of the target range. ${ }^{120}$ The CSII can provide long-term glycemic control while reducing hypoglycemic episodes and glycemic variability, improving lifestyle flexibility for patients and their families. ${ }^{121}$ A systematic review of randomized clinical trials comparing the effectiveness of insulin delivery systems and glucose-monitoring modalities in patients with diabetes 
receiving intensive insulin therapy was conducted by the Agency for Healthcare Research and Quality. The authors reported that both CSII and multiple daily injections have similar effectiveness on glycemic control and severe hypoglycemia in children and adolescents with T1DM and in adults with T2DM. ${ }^{122}$

Many technological advances have been made to older-generation pumps to increase the appeal of pump therapy. ${ }^{123}$ Currently available insulin pumps are discreet, ergonomic, and water resistant. Additionally, the Bolus Wizard ${ }^{\circledR}$ Calculator (Medtronic, Northridge, CA, USA) is a technology specific to insulin pumps that helps patients calculate the bolus insulin dose, based on a blood glucose reading. A tubing-free patch pump that adheres directly to the skin is a new trend in the design of insulin pumps. ${ }^{123}$ Alternate routes of insulin delivery that are currently in development, such as inhaled, buccal, oral, and transdermal, may also address clinician- and patient-based challenges to insulin acceptance and adherence in the future. Another potential technological advancement could be the use of closed-loop insulin delivery, but unfortunately it has only been studied extensively in patients with T1DM. The only study published that included insulin-naïve patients with T2DM ( $n=7)$ concluded that use of closed-loop insulin delivery is both feasible and safe in this patient population. ${ }^{124}$

\section{Meeting challenges of insulin therapy}

\section{Roles of patient and clinician in managing insulin therapy}

Patient education concerning the critical role of insulin therapy in diabetes management and energy homeostasis is essential to achieving glycemic control. Clinicians should destigmatize patients to insulin early on in the course of the disease as they guide their patients through the decisionmaking process. As discussed earlier, many obstacles in diabetes management and insulin intensification can be overcome by actively listening to patients to understand their fears and concerns. ${ }^{31}$

Prior to initiating insulin therapy, physicians must outline the goals of the therapy to their patients and explain how these goals will impact their self-management of T2DM and that to achieve treatment goals, diabetes management has to be individualized. For example, if patients are selftitrating their insulin, they must consider when they should inject their mealtime insulin, depending on the formulation they are using. One strategy the clinician can employ is to explain both the physiology and product profile of the insulin therapy that has been selected in the patient's individualized treatment plan. This discussion can bring attention to the treatment options available to the patient and educate and engage the patient in the treatment plan. Both clinicians and patients may be more accepting of insulin therapy if patients are well-informed about their treatment and do not fear it.

As patient education is a time consuming task for physicians, ${ }^{27} \mathrm{CDEs}$ can be invaluable in educating patients about glucose monitoring, insulin injection techniques, insulin storage, and the recognition and treatment of hypoglycemia. Communication between physicians, CDEs, and patients should be timely and constructive. Physicians can also enlist office personnel (eg, medical assistants) in educating patients about insulin treatment and training patients on the use of insulin pens or syringes, on selftitration, and the administration of first injections. Online educational tools are also available to assist providers in educating themselves and their patients. These resources can focus on: promoting a better understanding of diabetes as a disease state; demonstrating the use of insulin pens; explaining how and when to take medications, monitoring blood glucose and treating hypoglycemia; promoting the importance of adhering to diet and exercise; and engaging the patients in their own treatment process.

Empowering patients to take greater control of their diabetes by living a healthier lifestyle and facilitating selfmanagement may improve glycemic control and reduce the risk of complications. ${ }^{125}$ Enhancing quality of life, particularly through diet, makes patients feel better and has a positive feedback effect on their self-management. Teaching patients the importance of self-monitoring of blood glucose (SMBG) and how to use it as a guide for adjusting therapy can allow patients to be in control of their care. Adherence to SMBG is enhanced when the patient understands why each check is made, knows what specific action to take with that result, and observes first-hand the benefits of self-management as their glucose control improves and they begin to feel better.

Dosing adjustments using self-titration algorithms based on frequent SMBG monitoring have been shown to be effective for improving glycemic control and achieving target $\mathrm{HbA}_{1 \mathrm{c}}$ levels. ${ }^{126,127}$ Treatment with detemir using a simplified, patient-adjusted dosing algorithm (303 Algorithm) achieved comparable glycemic control with patients using standardof-care physician-driven adjustments with a minimal risk of hypoglycemia and weight gain. ${ }^{127}$ Although there was a higher rate (events/patient/year) of hypoglycemia in the patientadjusted dosing group compared to the physician-adjusted dosing group, these rates were significantly lower than at 
baseline in both groups ( 9.05 versus 6.44 for the patientadjusted dosing group [ $P=0.0039]$ and 9.53 versus 4.95 for the physician-adjusted dosing group $[P<0.0001]) .{ }^{127}$

Patients must understand that T2DM is a progressive disease that requires prevention and treatment to avoid development of serious complications. ${ }^{128}$ Patients should be brought up-to-date about the advances in technology and the relative ease of use of currently available insulin regimens and delivery systems, such as the small size of the needles in today's pen devices, ${ }^{129}$ which might help dispel the perceived notion of pain and discomfort associated with injection. Importantly, patients must take greater control toward their diabetes management.

\section{Individualizing insulin management: matching insulin to patient}

The 2012 ADA/EASD guidelines emphasize the importance of a patient-centered approach in the management of diabetes as the cornerstone of treatment success. ${ }^{13}$ Therefore, it is imperative that clinicians optimize insulin management and overcome the challenges to individualized insulin therapy to meet the patient's lifestyle and specific health care needs.

To appropriately individualize therapy, particularly for insulin-naïve patients, clinicians should consider the patient's glucose profile and residual endogenous insulin level, in addition to such practical considerations as treatment flexibility, convenience, cost, lifestyle, and the patient's cognitive and functional abilities. If the patient can still produce endogenous insulin, a combination of insulin therapy with oral antidiabetes agents or injectable incretins may reduce the required dose of insulin and limit weight gain. FPG levels and the magnitude of PPG excursions are also important factors to consider when titrating therapy. For example, for patients with elevated PPG, rapid-acting or prandial insulins, which have a much quicker onset of action and a shorter duration of action than RHI with less variability in absorption, control PPG and reduce the risk for late hypoglycemia. ${ }^{59,76}$ In addition, understanding that both fasting hyperglycemia and postprandial hyperglycemia contribute to elevated $\mathrm{HbA}_{1 \mathrm{c}}$ levels may help clinicians individualize insulin therapy and make adjustments where required. Measuring PPG levels may help identify when to treat patients who have $\mathrm{HbA}_{1 \mathrm{c}}$ levels that are borderline high due to postprandial hyperglycemia. Accordingly, both the AACE and ACE recommend treating to a 2-hour PPG target of $<140 \mathrm{mg} / \mathrm{dL}(<7.8 \mathrm{mmol} / \mathrm{L}){ }^{130}$ As patients approach target $\mathrm{HbA}_{1 \mathrm{c}}$ levels, PPG levels may contribute more to $\mathrm{HbA}_{1 \mathrm{c}}$ than FPG levels. As hyperglycemia worsens, the contribution of FPG increases. ${ }^{131}$
In a study of 1,699 patients with T2DM in whom $\mathrm{HbA}_{1 \mathrm{c}}$ was $>7.0 \%(>53.0 \mathrm{mmol} / \mathrm{mol})$ despite diet and oral antidiabetes therapy, basal/fasting hyperglycemia (BHG) accounted for the majority of hyperglycemia exposure $(76 \%-80 \%)$ across a wide range of $\mathrm{HbA}_{1 \mathrm{c}}$ values. ${ }^{132}$ Intensification of treatment with basal insulin led to lower mean $\mathrm{HbA}_{1 \mathrm{c}}$ levels, and the contribution from BHG was reduced, but it still accounted for approximately one-third of exposure. ${ }^{132}$ These findings indicate that for most patients not achieving $\mathrm{HbA}_{1 \mathrm{c}}$ goals with oral antidiabetes agents, targeting BHG with basal insulin or other treatment methods may be more effective than targeting postprandial hyperglycemia. However, to achieve optimal glycemic control, both BHG and postprandial hyperglycemia will need to be managed properly. ${ }^{132}$

\section{Identifying candidates for insulin pump therapy}

Even though CSII can be a suitable option for patients with T2DM, any given CSII regimen must effectively reduce glucose levels and be simple, unobtrusive, and costeffective. ${ }^{120}$ CSII may be best suited for technology-savvy patients with T1DM or T2DM who require multiple daily injections and who experience severe hypoglycemia or wide fluctuations in blood glucose levels throughout the day. ${ }^{133}$ Simple insulin dosing with CSII in patients with T2DM leads to improvements in glucose control, clinical outcomes, quality of life, and treatment satisfaction measures. ${ }^{120,134-136}$ In addition, comprehensive patient education and frequent SMBG or continuous glucose monitoring are necessary components of successful insulin pump therapy.

\section{Discussion}

Due to the pathogenesis and progressive nature ofT2DM, most noninsulin therapies will not be sufficient in managing diabetes over time, ${ }^{9}$ and the majority of patients will ultimately require insulin therapy. However, despite its efficacy, insulin therapy is underutilized due to easily avoidable, various clinician-, patient-, and health care system-related challenges.

Educating patients early about the critical role of insulin therapy in diabetes management and destigmatizing its use can help to overcome patient-related challenges and promote patient adherence and self-management. As part of a comprehensive educational strategy, clinicians should actively listen to patients and proactively address their concerns that can hinder both the initiation and adherence of insulin therapy. Emphasizing the relative ease associated with today's insulin regimens and delivery systems is an essential element of patient education. Empowering 
patients to take greater control of their diabetes management and heeding the ADA/EASD patient-centric approach to care can improve glycemic control and reduce the risk of complications. ${ }^{13,28,125,127,137}$ Physicians should also enlist the services of a CDE or other trained staff member to assist with patient education.

Achieving glycemic control soon after a diagnosis of diabetes is important to avoid complications. ${ }^{5}$ Individualizing insulin therapy to a regimen that is compatible with the patient's glucose profile and residual insulin secretion and that meets the patient's specific health care needs and lifestyle is another strategy clinicians can employ to overcome challenges to achieving glycemic control, keeping in mind that glycemic control can be more or less stringent depending on patient type. ${ }^{13}$ Insulin pen devices can help ease and simplify administration while the use of insulin analogs can help reduce the risk of hypoglycemia. Insulins that are not associated with weight gain (eg, detemir) can be useful in cases where the potential for weight gain could impact adherence or clinical outcomes. Clinicians must strive to remain informed of emerging new insulin analog options that have the potential to simplify and improve adherence to insulin therapy while optimizing glycemic control and mitigating risks. Finally, insulin pumps are often underutilized yet are an appropriate treatment option for both T1DM and T2DM, because they offer the most physiologic and convenient way to manage basal-bolus insulin.

\section{Conclusion}

Insulin is the most effective therapy available for managing hyperglycemia; however, hypoglycemia is a common and serious adverse event. Recent evidence suggests that initiating insulin earlier in the course of T2DM may provide important benefits, such as improved glycemic control, which may prevent or delay the development of diabetesrelated complications. The physiologic profile of basal insulin analogs, as well as other new insulin formulations, may offer clinicians options to address the hypoglycemia challenge of insulin therapy and to provide patients with multiple options to manage their disease and to fit their lifestyle.

\section{Acknowledgments}

Funding to support the preparation of this manuscript was provided by Novo Nordisk Inc. Novo Nordisk also provided a medical accuracy review of the first draft of the manuscript.
The authors thank Nicole Cooper and Heba H Costandy, MD, MS, of MedVal Scientific Information Services, LLC, for providing medical writing and editorial assistance. This manuscript was prepared according to the International Society for Medical Publication Professionals' Good Publication Practice for Communicating Company-Sponsored Medical Research: the GPP2 Guidelines.

\section{Author contributions}

Each author was involved in literature analysis/interpretation and in drafting and critically revising the manuscript. Both authors reviewed the final manuscript and gave approval for submission.

\section{Disclosure}

$\mathrm{CS}$ has received grant research funds from Bristol-Myers Squibb, Eli Lilly, GI Dynamics, and Sanofi-Aventis. CS is also a consultant/advisor to GI Dynamics and a member of the speakers bureau for Amylin, Boehringer Ingelheim, and Novo Nordisk. MKH is a consultant/advisor to Novo Nordisk and a member of the speakers bureau for Novo Nordisk.

\section{References}

1. Heller S, Kozlovski P, Kurtzhals P. Insulin's 85th anniversary-An enduring medical miracle. Diabetes Res Clin Pract. 2007;78(2):149-158.

2. Turner RC, Cull CA, Frighi V, Holman RR. Glycemic control with diet, sulfonylurea, metformin, or insulin in patients with type 2 diabetes mellitus: progressive requirement for multiple therapies (UKPDS 49). UK Prospective Diabetes Study (UKPDS) Group. JAMA. 1999;281(21): 2005-2012.

3. UKPDS 28: a randomized trial of efficacy of early addition of metformin in sulfonylurea-treated type 2 diabetes. UK Prospective Diabetes Study Group. Diabetes Care. 1998;21(1):87-92.

4. Weng J, Li Y, Xu W, et al. Effect of intensive insulin therapy on betacell function and glycaemic control in patients with newly diagnosed type 2 diabetes: a multicentre randomised parallel-group trial. Lancet. 2008;371(9626):1753-1760.

5. Le Floch JP. Critical appraisal of the safety and efficacy of insulin detemir in glycemic control and cardiovascular risk management in diabetics. Diabetes Metab Syndr Obes. 2010;3:197-213.

6. Dailey G. New strategies for basal insulin treatment in type 2 diabetes mellitus. Clin Ther. 2004;26(6):889-901.

7. Garvey WT, Olefsky JM, Griffin J, Hamman RF, Kolterman OG. The effect of insulin treatment on insulin secretion and insulin action in type II diabetes mellitus. Diabetes. 1985;34(3):222-234.

8. Robertson RP, Olson LK, Zhang HJ. Differentiating glucose toxicity from glucose desensitization: a new message from the insulin gene. Diabetes. 1994;43(9):1085-1089.

9. Wright A, Burden AC, Paisey RB, Cull CA, Holman RR; UK Prospective Diabetes Study Group. Sulfonylurea inadequacy: efficacy of addition of insulin over 6 years in patients with type 2 diabetes in the UK Prospective Diabetes Study (UKPDS 57). Diabetes Care. 2002;25(2):330-336.

10. Skyler JS, Bergenstal R, Bonow RO, et al; American Diabetes Association; American College of Cardiology Foundation; American Heart Association. Intensive glycemic control and the prevention of cardiovascular events: implications of the ACCORD, ADVANCE, and VA Diabetes Trials: a position statement of the American Diabetes Association and a Scientific Statement of the American College of Cardiology Foundation and the American Heart Association. J Am Coll Cardiol. 2009;53(3):298-304. 
11. Gerstein HC, Bosch J, Dagenais GR, et al; ORIGIN Trial Investigators. Basal insulin and cardiovascular and other outcomes in dysglycemia. N Engl J Med. 2012;367(4):319-328.

12. Mellbin LG, Rydén L, Riddle MC, et al; ORIGIN Trial Investigators. Does hypoglycaemia increase the risk of cardiovascular events? A report from the ORIGIN trial. Eur Heart J. 2013;34(40): 3137-3144.

13. Inzucchi SE, Bergenstal RM, Buse JB, et al; American Diabetes Association (ADA); European Association for the Study of Diabetes (EASD). Management of hyperglycemia in type 2 diabetes: a patientcentered approach: position statement of the American Diabetes Association (ADA) and the European Association for the Study of Diabetes (EASD). Diabetes Care. 2012;35(6):1364-1379.

14. American Diabetes Association. Standards of medical care in diabetes 2014. Diabetes Care. 2014;37 Suppl 1:S14-S80.

15. Ismail-Beigi F, Moghissi E, Tiktin M, Hirsch IB, Inzucchi SE, Genuth S. Individualizing glycemic targets in type 2 diabetes mellitus: implications of recent clinical trials. Ann Intern Med. 2011;154(8) 554-559.

16. Cheung BM, Ong KL, Cherny SS, Sham PC, Tso AW, Lam KS. Diabetes prevalence and therapeutic target achievement in the United States, 1999 to 2006. Am J Med. 2009;122(5):443-453.

17. American Diabetes Association. Standards of medical care in diabetes - 2011. Diabetes Care. 2011;34 Suppl 1:S11-S61.

18. Simonson GD, Cuddihy RM, Reader D, Bergenstal RM. International Diabetes Center Treatment of Type 2 Diabetes Glucose Algorithm. Diabetes Management. 2011;1(2):175-189.

19. Rodbard HW, Jellinger PS, Davidson JA, et al. Statement by an American Association of Clinical Endocrinologists/American College of Endocrinology consensus panel on type 2 diabetes mellitus: an algorithm for glycemic control. Endocr Pract. 2009;15(6): 540-559.

20. Spann SJ, Nutting PA, Galliher JM, et al. Management of type 2 diabetes in the primary care setting: a practice-based research network study. Ann Fam Med. 2006;4(1):23-31.

21. Karter AJ, Subramanian U, Saha C, et al. Barriers to insulin initiation: the translating research into action for diabetes insulin starts project. Diabetes Care. 2010;33(4):733-735.

22. Peyrot M, Rubin RR, Kruger DF, Travis LB. Correlates of insulin injection omission. Diabetes Care. 2010;33(2):240-245.

23. Phillips LS, Branch WT, Cook CB, et al. Clinical inertia. Ann Intern Med. 2001;135(9):825-834.

24. el-Kebbi IM, Ziemer DC, Gallina DL, Dunbar V, Phillips LS. Diabetes in urban African-Americans. XV. Identification of barriers to provider adherence to management protocols. Diabetes Care. 1999;22(10): 1617-1620.

25. Brown JB, Nichols GA, Perry A. The burden of treatment failure in type 2 diabetes. Diabetes Care. 2004;27(7):1535-1540.

26. Cuddihy RM, Philis-Tsimikas A, Nazeri A. Type 2 diabetes care and insulin intensification: is a more multidisciplinary approach needed? Results from the MODIFY survey. Diabetes Educ. 2011;37(1): 111-123.

27. Hayes RP, Fitzgerald JT, Jacober SJ. Primary care physician beliefs about insulin initiation in patients with type 2 diabetes. Int J Clin Pract. 2008;62(6):860-868.

28. LaSalle JR. Empowering patients during insulin initiation: a real-world approach. J Am Osteopath Assoc. 2010;110(2):69-78.

29. Brunton S, Gough S, Hicks D, et al. A look into the future: improving diabetes care by 2015. Curr Med Res Opin. 2011;27 Suppl 3: 65-72.

30. American Diabetes Association. Standards of medical care in diabetes - 2013. Diabetes Care. 2013;36 Suppl 1:S11-S66.

31. Benroubi M. Fear, guilt feelings and misconceptions: barriers to effective insulin treatment in type 2 diabetes. Diabetes Res Clin Pract. 2011;93 Suppl 1:S97-S99.

32. Cryer PE. Hypoglycemia in Diabetes: Pathophysiology, Prevalence, and Prevention. Alexandria, VA: American Diabetes Association; 2009.
33. Workgroup on Hypoglycemia, American Diabetes Association. Defining and reporting hypoglycemia in diabetes: a report from the American Diabetes Association Workgroup on Hypoglycemia. Diabetes Care. 2005;28(5):1245-1249.

34. Brod M, Christensen T, Thomsen TL, Bushnell DM. The impact of non-severe hypoglycemic events on work productivity and diabetes management. Value Health. 2011;14(5):665-671.

35. Miller CD, Phillips LS, Ziemer DC, Gallina DL, Cook CB, El-Kebbi IM. Hypoglycemia in patients with type 2 diabetes mellitus. Arch Intern Med. 2001;161(13):1653-1659.

36. Vexiau P, Mavros P, Krishnarajah G, Lyu R, Yin D. Hypoglycaemia in patients with type 2 diabetes treated with a combination of metformin and sulphonylurea therapy in France. Diabetes Obes Metab. 2008; 10 Suppl 1:16-24.

37. Pramming S, Thorsteinsson B, Bendtson I, Binder C. Symptomatic hypoglycaemia in 411 type 1 diabetic patients. Diabet Med. 1991;8(3): 217-222.

38. Unger J, Parkin C. Hypoglycemia in insulin-treated diabetes: a case for increased vigilance. Postgrad Med. 2011;123(4):81-91.

39. Brunton SA. Nocturnal hypoglycemia: answering the challenge with long-acting insulin analogs. MedGenMed. 2007;9(2):38.

40. Allen KV, Frier BM. Nocturnal hypoglycemia: clinical manifestations and therapeutic strategies toward prevention. Endocr Pract. 2003;9(6): 530-543.

41. Riddle MC, Rosenstock J, Gerich J; Insulin Glargine 4002 Study Investigators. The treat-to-target trial: randomized addition of glargine or human NPH insulin to oral therapy of type 2 diabetic patients. Diabetes Care. 2003;26(11):3080-3086.

42. Rosenstock J, Dailey G, Massi-Benedetti M, Fritsche A, Lin Z, Salzman A. Reduced hypoglycemia risk with insulin glargine: a meta-analysis comparing insulin glargine with human NPH insulin in type 2 diabetes. Diabetes Care. 2005;28(4):950-955.

43. Rosenstock J, Schwartz SL, Clark CM, Park GD, Donley DW, Edwards MB. Basal insulin therapy in type 2 diabetes: 28-week comparison of insulin glargine (HOE 901) and NPH insulin. Diabetes Care. 2001;24(4):631-636.

44. Haak T, Tiengo A, Draeger E, Suntum M, Waldhäusl W. Lower withinsubject variability of fasting blood glucose and reduced weight gain with insulin detemir compared to NPH insulin in patients with type 2 diabetes. Diabetes Obes Metab. 2005;7(1):56-64.

45. Little S, Shaw J, Home P. Hypoglycemia rates with basal insulin analogs. Diabetes Technol Ther. 2011;13 Supp1 1:S53-S64.

46. Levin PA, Mersey JH, Zhou S, Bromberger LA. Clinical outcomes using long-term combination therapy with insulin glargine and exenatide in patients with type 2 diabetes mellitus. Endocr Pract. 2012;18(1):17-25.

47. Schappert SM, Rechtsteiner EA. Ambulatory medical care utilization estimates for 2007. Vital Health Stat. 2011;(169):1-38.

48. Greaves CJ, Brown P, Terry RT, Eiser C, Lings P, Stead JW. Converting to insulin in primary care: an exploration of the needs of practice nurses. J Adv Nurs. 2003;42(5):487-496.

49. Frid A, Hirsch L, Gaspar R, et al; Scientific Advisory Board for the Third Injection Technique Workshop. New injection recommendations for patients with diabetes. Diabetes Metab. 2010;36 Suppl 1: S3-S18.

50. Nakar S, Yitzhaki G, Rosenberg R, Vinker S. Transition to insulin in Type 2 diabetes: family physicians' misconception of patients' fears contributes to existing barriers. J Diabetes Complications. 2007;21(4): 220-226.

51. Polonsky WH, Fisher L, Guzman S, Villa-Caballero L, Edelman SV. Psychological insulin resistance in patients with type 2 diabetes: the scope of the problem. Diabetes Care. 2005;28(10):2543-2545.

52. Meece J. Dispelling myths and removing barriers about insulin in type 2 diabetes. Diabetes Educ. 2006;32(Suppl 1):9S-18S

53. Donnan PT, MacDonald TM, Morris AD. Adherence to prescribed oral hypoglycaemic medication in a population of patients with Type 2 diabetes: a retrospective cohort study. Diabet Med. 2002;19(4):279-284. 
54. Peyrot M, Barnett AH, Meneghini LF, Schumm-Draeger PM. Insulin adherence behaviours and barriers in the multinational Global Attitudes of Patients and Physicians in Insulin Therapy study. Diabet Med. 2012;29(5):682-689.

55. Ratner R, Wynne A, Nakhle S, Brusco O, Vlajnic A, Rendell M. Influence of preprandial vs postprandial insulin glulisine on weight and glycaemic control in patients initiating basal-bolus regimen for type 2 diabetes: a multicenter, randomized, parallel, open-label study (NCT00135096). Diabetes Obes Metab. 2011;13(12):1142-1148.

56. Meneghini L, Mersebach H, Kumar S, Svendsen AL, Hermansen K. Comparison of 2 intensification regimens with rapid-acting insulin aspart in type 2 diabetes mellitus inadequately controlled by once-daily insulin detemir and oral antidiabetes drugs: the step-wise randomized study. Endocr Pract. 2011;17(5):727-736.

57. Raccah D, Haak T, Huet D, et al. Stepwise intensification of prandial insulin versus basal-bolus insulin therapy in patients with type 2 diabetes mellitus [abstract]. Diabetologia. 2010;53(Suppl 1):S382.

58. Hirsch IB. Insulin analogues. N Engl J Med. 2005;352(2):174-183.

59. Vázquez-Carrera M, Silvestre JS. Insulin analogues in the management of diabetes. Methods Find Exp Clin Pharmacol. 2004;26(6):445-461.

60. Ulrich H, Snyder B, Garg SK. Combining insulins for optimal blood glucose control in type I and 2 diabetes: focus on insulin glulisine. Vasc Health Risk Manag. 2007;3(3):245-254.

61. Home PD, Lindholm A, Hylleberg B, Round P. Improved glycemic control with insulin aspart: a multicenter randomized double-blind crossover trial in type 1 diabetic patients. UK Insulin Aspart Study Group. Diabetes Care. 1998;21(11):1904-1909.

62. Anderson JH Jr, Brunelle RL, Koivisto VA, Trautmann ME, Vignati L, DiMarchi R. Improved mealtime treatment of diabetes mellitus using an insulin analogue. Multicenter Insulin Lispro Study Group. Clin Ther. 1997;19(1):62-72.

63. Hartman I. Insulin analogs: impact on treatment success, satisfaction, quality of life, and adherence. Clin Med Res. 2008;6(2):54-67.

64. Heinemann L, Linkeschova R, Rave K, Hompesch B, Sedlak M, Heise T. Time-action profile of the long-acting insulin analog insulin glargine (HOE901) in comparison with those of NPH insulin and placebo. Diabetes Care. 2000;23(5):644-649.

65. Suzuki D, Toyoda M, Kondo M, et al. Efficacy of long-acting insulin analog insulin glargine at high dosage for basal-bolus insulin therapy in patients with type 2 diabetes. Tokai J Exp Clin Med. 2012;37(2): $35-40$.

66. Raskin P, Gylvin T, Weng W, Chaykin L. Comparison of insulin detemir and insulin glargine using a basal-bolus regimen in a randomized, controlled clinical study in patients with type 2 diabetes. Diabetes Metab Res Rev. 2009;25(6):542-548.

67. Plank J, Bodenlenz M, Sinner F, et al. A double-blind, randomized, dose-response study investigating the pharmacodynamic and pharmacokinetic properties of the long-acting insulin analog detemir. Diabetes Care. 2005;28(5):1107-1112.

68. Klein O, Lynge J, Endahl L, Damholt B, Nosek L, Heise T. Albuminbound basal insulin analogues (insulin detemir and NN344): comparable time-action profiles but less variability than insulin glargine in type 2 diabetes. Diabetes Obes Metab. 2007;9(3):290-299.

69. Lepore M, Pampanelli S, Fanelli C, et al. Pharmacokinetics and pharmacodynamics of subcutaneous injection of long-acting human insulin analog glargine, NPH insulin, and ultralente human insulin and continuous subcutaneous infusion of insulin lispro. Diabetes. 2000;49(12): 2142-2148.

70. Meneghini L, Atkin SL, Bain S, et al. Flexible once-daily dosing of insulin degludec does not compromise glycemic control or safety compared to insulin glargine given once daily at the same time each day in people with type 2 diabetes. Diabetes. 2011;60 Suppl 1:LB10-LB11.

71. Russell-Jones DL, Hollander P, Miranda-Palma B. Altering the time of day of once-daily dosing of insulin degludec achieves similar glycemic control and safety compared to dosing the same time of day in people with type 1 diabetes. Diabetes. 2012;61 Suppl 1:A91.
72. Mathieu C, Hollander P, Miranda-Palma B, et al. Insulin degludec allows for flexible daily dosing in type 1 diabetes, providing equal glycemic control with less nocturnal hypoglycemia than insulin glargine over 52 weeks. Can J Diabetes. 2012;36(5):S56-S57.

73. Hirsch L, Gibney M, Berube J, Manocchio J. Impact of a modified needle tip geometry on penetration force as well as acceptability, preference, and perceived pain in subjects with diabetes. J Diabetes Sci Technol. 2012;6(2):328-335.

74. Korytkowski M, Bell D, Jacobsen C, Suwannasari R; FlexPen Study Team. A multicenter, randomized, open-label, comparative, two-period crossover trial of preference, efficacy, and safety profiles of a prefilled, disposable pen and conventional vial/syringe for insulin injection in patients with type 1 or 2 diabetes mellitus. Clin Ther. 2003;25(11): 2836-2848.

75. Flood T. Advances in insulin delivery systems and devices: beyond the vial and syringe. Insulin. 2006;1(3):99-108.

76. Cobble ME. Initiating and intensifying insulin therapy for type 2 diabetes: why, when, and how. Am J Ther. 2009;16(1):56-64.

77. Peyrot M, Rubin RR, Lauritzen T, et al; International DAWN Advisory Panel. Resistance to insulin therapy among patients and providers: results of the cross-national Diabetes Attitudes, Wishes, and Needs (DAWN) study. Diabetes Care. 2005;28(11):2673-2679.

78. Polonsky WH, Hajos TR, Dain MP, Snoek FJ. Are patients with type 2 diabetes reluctant to start insulin therapy? An examination of the scope and underpinnings of psychological insulin resistance in a large, international population. Curr Med Res Opin. 2011;27(6):1169-1174.

79. Marrero DG. Overcoming patient barriers to initiating insulin therapy in type 2 diabetes mellitus. Clin Cornerstone. 2007;8(2):33-40; discussion $41-43$.

80. Cameron CG, Bennett HA. Cost-effectiveness of insulin analogues for diabetes mellitus. CMAJ. 2009;180(4):400-407.

81. Tunis SL, Minshall ME, Conner C, et al. Cost-effectiveness of insulin detemir compared to NPH insulin for type 1 and type 2 diabetes mellitus in the Canadian payer setting: modeling analysis. Curr Med Res Opin. 2009;25(5):1273-1284.

82. Tunis SL, Sauriol L, Minshall ME. Cost effectiveness of insulin glargine plus oral antidiabetes drugs compared with premixed insulin alone in patients with type 2 diabetes mellitus in Canada. Appl Health Econ Health Policy. 2010;8(4):267-280.

83. Bullano MF, Al-Zakwani IS, Fisher MD, Menditto L, Willey VJ. Differences in hypoglycemia event rates and associated cost-consequence in patients initiated on long-acting and intermediate-acting insulin products. Curr Med Res Opin. 2005;21(2):291-298.

84. Borah BJ, Darkow T, Bouchard J, Aagren M, Forma F, Alemayehu B. A comparison of insulin use, glycemic control, and health care costs with insulin detemir and insulin glargine in insulin-naive patients with type 2 diabetes. Clin Ther. 2009;31(3):623-631.

85. Charbonnel B, Penfornis A, Varroud-Vial M, Kusnik-Joinville O, Detournay B. Insulin therapy for diabetes mellitus: treatment regimens and associated costs. Diabetes Metab. 2012;38(2):156-163.

86. Gu Q, Zeng F, Patel BV, Tripoli LC. Part D coverage gap and adherence to diabetes medications. Am J Manag Care. 2010;16(12):911-918.

87. Bonafede MM, Kalsekar A, Pawaskar M, et al. Insulin use and persistence in patients with type 2 diabetes adding mealtime insulin to a basal regimen: a retrospective database analysis. BMC Endocr Disord. 2011;11:3.

88. Lee WC, Balu S, Cobden D, Joshi AV, Pashos CL. Copayment level and medication adherence in type 2 diabetes patients managed with insulin aspart pen therapy [abstract]. Value Health. 2007;10:A63.

89. Aydin CM, Taylor R, Billington EO, Tildesley HD. Insulin therapy is no cheaper than thiazolidinedione therapy in patients with type 2 diabetes. BC Med J. 2006;48(8):392-398.

90. Meneghini L. Advances in insulin therapy: physiological replacement with insulin analogs. US Endocrinol. 2007;1:27-28.

91. Søndergaard LG, Stoltenberg M, Flyvbjerg A, et al. Zinc ions in beta-cells of obese, insulin-resistant, and type 2 diabetic rats traced by autometallography. APMIS. 2003;111(12):1147-1154. 
92. Dailey G, Rosenstock J, Moses RG, Ways K. Insulin glulisine provides improved glycemic control in patients with type 2 diabetes. Diabetes Care. 2004;27(10):2363-2368.

93. Pala L, Mannucci E, Dicembrini I, Rotella CM. A comparison of mealtime insulin aspart and human insulin in combination with metformin in type 2 diabetes patients. Diabetes Res Clin Pract. 2007;78(1):132-135.

94. Heise T, Nosek L, Rønn BB, et al. Lower within-subject variability of insulin detemir in comparison to NPH insulin and insulin glargine in people with type 1 diabetes. Diabetes. 2004;53(6):1614-1620.

95. Meneghini LF, Orozco-Beltran D, Khunti K, et al. Weight beneficial treatments for type 2 diabetes. J Clin Endocrinol Metab. 2011;96(11):3337-3353.

96. Yki-Järvinen H, Dressler A, Ziemen M; HOE 901/300s Study Group. Less nocturnal hypoglycemia and better post-dinner glucose contro with bedtime insulin glargine compared with bedtime NPH insulin during insulin combination therapy in type 2 diabetes. HOE 901/3002 Study Group. Diabetes Care. 2000;23(8):1130-1136.

97. Hermansen K, Davies M, Derezinski T, Martinez Ravn G, Clauson P, Home P. A 26-week, randomized, parallel, treat-to-target trial comparing insulin detemir with NPH insulin as add-on therapy to oral glucose-lowering drugs in insulin-naive people with type 2 diabetes. Diabetes Care. 2006;29(6):1269-1274.

98. Heise T, Tack CJ, Cuddihy R, et al. A new-generation ultra-long-acting basal insulin with a bolus boost compared with insulin glargine in insulin-naive people with type 2 diabetes: a randomized, controlled trial. Diabetes Care. 2011;34(3):669-674.

99. Heise T, Pieber TR. Towards peakless, reproducible and long-acting insulins. An assessment of the basal analogues based on isoglycaemic clamp studies. Diabetes Obes Metab. 2007;9(5):648-659.

100. Shanik MH. Intensifying insulin therapy with insulin analog premixes: transitioning from basal insulin in type 2 diabetes. Diabetes Technol Ther. 2012;14(6):533-539.

101. Boehm BO, Home PD, Behrend C, Kamp NM, Lindholm A. Premixed insulin aspart 30 vs premixed human insulin 30/70 twice daily: a randomized trial in Type 1 and Type 2 diabetic patients. Diabet Med. 2002;19(5):393-399.

102. Garber AJ. Premixed insulin analogues for the treatment of diabetes mellitus. Drugs. 2006;66(1):31-49.

103. Roach P, Yue L, Arora V. Improved postprandial glycemic control during treatment with Humalog Mix25, a novel protamine-based insulin lispro formulation. Humalog Mix25 Study Group. Diabetes Care. 1999;22(8):1258-1261.

104. Tibaldi JT. Biphasic insulin aspart 70/30 three times a day in older patients with type 2 diabetes not achieving optimal glycemic control on a twice-daily regimen: a retrospective case series analysis from clinical practice. Adv Ther. 2007;24(6):1348-1356.

105. Kilo C, Mezitis N, Jain R, Mersey J, McGill J, Raskin P. Starting patients with type 2 diabetes on insulin therapy using once-daily injections of biphasic insulin aspart 70/30, biphasic human insulin $70 / 30$, or NPH insulin in combination with metformin. J Diabetes Complications. 2003;17(6):307-313.

106. Arnolds S, Kuglin B, Kapitza C, Heise T. How pharmacokinetic and pharmacodynamic principles pave the way for optimal basal insulin therapy in type 2 diabetes. Int J Clin Pract. 2010;64(10) $1415-1424$.

107. Jonassen I, Havelund S, Ribel U, et al. Insulin degludec: multi-hexamer formation is the underlying basis for this new generation ultra-long acting basal insulin. Diabetologia. 2010;53(Suppl 1):S388.

108. Kurtzhals P, Heise T, Strauss HM, et al. Multi-hexamer formation is the underlying mechanism behind the ultra-long glucose-lowering effect of insulin degludec [abstract]. Diabetes. 2011;60(Suppl 1A):LB12.

109. Garber AJ, King AB, Del Prato S, et al; NN1250-3582 (BEGIN BB T2D) Trial Investigators. Insulin degludec, an ultra-longacting basal insulin, versus insulin glargine in basal-bolus treatment with mealtime insulin aspart in type 2 diabetes (BEGIN Basal-Bolus Type 2): a phase 3, randomised, open-label, treat-to-target non-inferiority trial. Lancet. 2012;379(9825):1498-1507.
110. Niskanen L, Leiter LA, Franek E, et al. Comparison of a soluble co-formulation of insulin degludec/insulin aspart vs biphasic insulin aspart 30 in type 2 diabetes: a randomised trial. Eur J Endocrinol. 2012;167(2):287-294.

111. Krasner A, Pohl R, Simms P, Pichotta P, Hauser R, De Souza E. A review of a family of ultra-rapid-acting insulins: formulation development. J Diabetes Sci Technol. 2012;6(4):786-796.

112. Pohl R, Hauser R, Li M, et al. Ultra-rapid absorption of recombinant human insulin induced by zinc chelation and surface charge masking. J Diabetes Sci Technol. 2012;6(4):755-763.

113. Castle JR, Morrow L, Pitts A, et al. Evaluations of modified ultra-rapid acting Linjeta $^{\mathrm{TM}}$ formulations BIOD-105 and BIOD-107 in patients with type 1 diabetes [abstract]. Diabetes. 2012;61(Suppl 1):A91.

114. Bergenstal RM, Rosenstock J, Arakaki RF, et al. A randomized, controlled study of once-daily LY2605541, a novel long-acting basal insulin, versus insulin glargine in basal insulin-treated patients with type 2 diabetes. Diabetes Care. 2012;35(11):2140-2147.

115. Anderson BJ, Redondo MJ. What can we learn from patient-reported outcomes of insulin pen devices? J Diabetes Sci Technol. 2011;5(6): $1563-1571$

116. Goldstein HH. Pen devices to improve patient adherence with insulin therapy in type 2 diabetes. Postgrad Med. 2008;120(3):172-179.

117. Cobden D, Lee WC, Balu S, Joshi AV, Pashos CL. Health outcomes and economic impact of therapy conversion to a biphasic insulin analog pen among privately insured patients with type 2 diabetes mellitus Pharmacotherapy. 2007;27(7):948-962.

118. Lee WC, Balu S, Cobden D, Joshi AV, Pashos CL. Medication adherence and the associated health-economic impact among patients with type 2 diabetes mellitus converting to insulin pen therapy: an analysis of third-party managed care claims data. Clin Ther. 2006;28(10):1712-1725; discussion 1710-1711.

119. Baser O, Bouchard J, DeLuzio T, Henk H, Aagren M. Assessment of adherence and healthcare costs of insulin device (FlexPen) versus conventional vial/syringe. Adv Ther. 2010;27(2):94-104.

120. Bode BW. Insulin pump use in type 2 diabetes. Diabetes Technol Ther. 2010;12 Suppl 1:S17-S21.

121. White RD. Insulin pump therapy (continuous subcutaneous insulin infusion). Prim Care. 2007;34(4):845-871, vii.

122. Golden SH, Sapir T. Methods for insulin delivery and glucose monitoring in diabetes: summary of a comparative effectiveness review. J Manag Care Pharm. 2012;18(Suppl 6):S1-S17.

123. Selam JL. Evolution of diabetes insulin delivery devices. J Diabetes Sci Technol. 2010;4(3):505-513.

124. Kumareswaran K, Thabit H, Leelarathna L, et al. Feasibility of closedloop insulin delivery in type 2 diabetes: a randomised controlled study. Diabetes Care. 2014;37(5):1198-1203.

125. Beyazit E, Mollaoğlu M. Investigation of effect on glycosylated hemoglobin, blood pressure, and body mass index of diabetes intensive education program in patients with type 2 diabetes mellitus Am J Mens Health. 2011;5(4):351-357.

126. Blonde L, Merilainen M, Karwe V, Raskin P; TITRATE Study Group. Patient-directed titration for achieving glycaemic goals using a once-daily basal insulin analogue: an assessment of two different fasting plasma glucose targets - the TITRATE study. Diabetes Obes Metab. 2009;11(6):623-631.

127. Meneghini L, Koenen C, Weng W, Selam JL. The usage of a simplified self-titration dosing guideline (303 Algorithm) for insulin detemir in patients with type 2 diabetes - results of the randomized, controlled PREDICTIVE 303 study. Diabetes Obes Metab. 2007;9(6) 902-913.

128. Campbell RK, Martin TM. The chronic burden of diabetes. Am J Manag Care. 2009;15(Supp1 9):S248-S254.

129. Meneghini L. Why and how to use insulin therapy earlier in the management of type 2 diabetes. South Med J. 2007;100(2):164-174

130. American Association of Clinical Endocrinologists. American College of Endocrinology consensus statement on guidelines for glycemic control. Endocr Pract. 2002;8(Suppl 1):5-11. 
131. Monnier L, Lapinski H, Colette C. Contributions of fasting and postprandial plasma glucose increments to the overall diurnal hyperglycemia of type 2 diabetic patients: variations with increasing levels of HbA(1c). Diabetes Care. 2003;26(3):881-885.

132. Riddle M, Umpierrez G, DiGenio A, Zhou R, Rosenstock J. Contributions of basal and postprandial hyperglycemia over a wide range of A1C levels before and after treatment intensification in type 2 diabetes. Diabetes Care. 2011;34(12):2508-2514.

133. Potti LG, Haines ST. Continuous subcutaneous insulin infusion therapy: A primer on insulin pumps. J Am Pharm Assoc (2003). 2009;49(1):e1-e13.

134. Edelman SV, Bode BW, Bailey TS, et al. Insulin pump therapy in patients with type 2 diabetes safely improved glycemic control using a simple insulin dosing regimen. Diabetes Technol Ther. 2010;12(8):627-633.
135. Labrousse-Lhermine F, Cazals L, Ruidavets JB, Hanaire H; GEDEC Study Group. Long-term treatment combining continuous subcutaneous insulin infusion with oral hypoglycaemic agents is effective in type 2 diabetes. Diabetes Metab. 2007;33(4):253-260.

136. Parkner T, Laursen T, Vestergaard ET, et al. Insulin and glucose profiles during continuous subcutaneous insulin infusion compared with injection of a long-acting insulin in Type 2 diabetes. Diabet Med. 2008;25(5):585-591.

137. Selam JL, Koenen C, Weng W, Meneghini L. Improving glycemic control with insulin detemir using the 303 Algorithm in insulin naïve patients with type 2 diabetes: a subgroup analysis of the US PREDICTIVE 303 study. Curr Med Res Opin. 2008;24(1): $11-20$.

\section{Publish your work in this journal}

The Journal of Multidisciplinary Healthcare is an international, peerreviewed open-access journal that aims to represent and publish research in healthcare areas delivered by practitioners of different disciplines. This includes studies and reviews conducted by multidisciplinary teams as well as research which evaluates the results or conduct of such teams or healthcare processes in general. The journal covers a wide range of areas and welcomes submission from practitioners at all levels, from all over the world. The manuscript management system is completely online and includes a very quick and fair peer-review system. Visit http://www.dovepress.com/testimonials.php to read real quotes from published authors. 